\title{
Opposing effects of bisphosphonates and advanced glycation end-products on osteoblastic cells
}

\author{
María Virginia Gangoiti, Ana María Cortizo, Verónica Arnol, \\ Juan Ignacio Felice, Antonio Desmond McCarthy * \\ Bioquímica Patológica, Facultad de Ciencias Exactas, Universidad Nacional de La Plata, Argentina
}

\section{A R T I C L E I N F O}

\section{Article history:}

Received 3 May 2008

Received in revised form 28 September 2008

Accepted 13 October 2008

Available online 21 October 2008

\section{Keywords:}

Bisphosphonates

Advanced glycation endproducts

Osteoblasts

Proliferation

Reactive oxygen species

\begin{abstract}
A B S T R A C T
Patients with long-standing Diabetes mellitus can develop osteopenia and osteoporosis. We have previously shown that advanced glycation endproducts reduce the bone-forming activity of osteoblasts. Bisphosphonates are used for the treatment of various bone disorders, since they reduce osteoclastic function and survival, and stimulate osteoblastic bone-forming capacity. In this work we have investigated whether bisphosphonates are able to revert advanced glycation endproducts-induced deleterious effects in osteoblasts. MC3T3E1 and UMR106 osteoblastic cells were incubated with control or advanced glycation endproducts-modified bovine serum albumin, in the presence or absence of different doses of the bisphosphonates Alendronate, Pamidronate or Zoledronate. After 24-72 h of culture, we evaluated their effects on cell proliferation and apoptosis, type-1 collagen production, alkaline and neutral phosphatase activity, and intracellular reactive oxygen species production. Advanced glycation endproducts significantly decreased osteoblast proliferation, alkaline phosphatase activity and type 1 collagen production, while increasing osteoblastic apoptosis and reactive oxygen species production. These effects were completely reverted by low doses $\left(10^{-8} \mathrm{M}\right)$ of bisphosphonates. High doses of bisphosphonates $\left(10^{-4}-10^{-5} \mathrm{M}\right)$ were toxic for osteoblasts. Nifedipine (L-type calcium channel blocker) did not affect the advanced glycation endproducts-induced decrease in osteoblastic proliferation, although it blocked the reversion of this effect by $10^{-8} \mathrm{M}$ Alendronate. Both advanced glycation endproducts and Alendronate inhibited the activity of intracellular neutral phosphatases. In conclusion, we show that bisphosphonates revert the deleterious actions of advanced glycation endproducts on osteoblastic cells, and that these effects of bisphosphonates depend on: (a) $\mathrm{Ca}^{2+}$ influx through L-type voltage-sensitive channels, and (b) blockage of advanced glycation endproducts-induced reactive oxygen species generation.
\end{abstract}

(c) 2008 Elsevier B.V. All rights reserved.

\section{Introduction}

Bisphosphonates are drugs which have been extensively used for the treatment of bone disorders such as osteoporosis, Paget's disease, and tumor-associated osteolysis and hypercalcemia (Rogers, 2003). Bisphosphonates have a similar chemical structure to that of inorganic pyrophosphate, in which the $\mathrm{P}-\mathrm{O}-\mathrm{P}$ bond, which links the two phosphate groups, is replaced by a carbon atom (P-C-P structure). Bisphosphonates have a structural motif in common, called the "bone hook", which consists of the two phosphonate groups that facilitate binding to bone mineral (Green, 2005). The exact molecular targets and mechanisms of action of bisphosphonates have remained unclear for more than 30 years, but have recently begun to be unraveled. Thus, bisphosphonates can be grouped into two classes with different

\footnotetext{
* Corresponding author. Cátedra de Bioquímica Patológica, Facultad de Ciencias Exactas, Universidad Nacional de La Plata, 47 y 115, (1900) La Plata, Argentina. Tel.: +54 221 4235333x49/33; fax: +54 2214223409.

E-mail address: mccarthy@biol.unlp.edu.ar (A.D. McCarthy).
}

molecular mechanisms of action. Nitrogen-containing bisphosphonates are the most potent kind, and act by inhibiting the mevalonate pathway, thereby preventing prenylation of small GTPase signaling proteins. On the other hand, bisphosphonates that lack a nitrogen in their chemical structure are less potent and have a different mode of action that may involve the formation of cytotoxic metabolites or inhibition of protein tyrosine phosphatases (Rogers et al., 2000).

Bisphosphonates have been shown to affect bone metabolism mainly by inhibiting osteoclast-mediated bone resorption (Rogers, 2003). More recently, increasing lines of evidence have also implicated other bone cell types such as osteoblasts as possible targets for direct and indirect action of bisphosphonates (Tsuchimoto et al., 1994; Viereck et al., 2002), although the precise mechanisms have not been elucidated. In this line of work, our group has previously shown a biphasic effect of bisphosphonates on osteoblastic growth and differentiation, with an increase in both parameters at low concentrations of bisphosphonates, and a decrease at $10^{-4}-10^{-5} \mathrm{M}$ (Vaisman et al., 2004). The latter decrease may be partly due to an inhibitory effect of bisphosphonates which we have shown on osteoblastic 
neutral phosphatases (Molinuevo et al., 2007) and on alkaline phosphatase via chelation of divalent cations (Vaisman et al., 2005). In a series of elegant experiments, Plotkin et al. $(1999,2006)$ have demonstrated that bisphosphonates can prevent osteoblast and osteocyte apoptosis in vivo and in vitro, and have proposed that their anti-fracture actions could result in part from a preservation of the integrity of the osteocyte network, and/or from an increase in the working time of bone forming cells.

Diabetes mellitus has been shown to affect the integrity and functionality of bone tissue (Bouillon, 1991; Schwartz, 2003). Patients with type 1 diabetes frequently show low bone mass (osteopenia) mainly caused by a decrease in bone formation, with a reduction in the number and activity of osteoblasts. On the other hand, type 2 diabetes is simultaneously associated both with an increase in bone mineral density, and with an increased risk of fracture and impaired bone healing (Schwartz et al., 2001; Strotmeyer et al., 2005), thus indicating an overall decrease in bone architecture and quality. It has recently been reported that diabetes enhances the apoptosis of fibroblasts and osteoblasts mainly by activating caspase- $8,-9$ and -3 expression and activity, which in turn may impair bone healing (Al-Mashat et al., 2006).

The accumulation of advanced glycation endproducts is believed to play a pathogenic role in the development of different long-term complications of both types of diabetes (Brownlee, 2005). Advanced glycation endproducts are slowly and irreversibly formed on proteins exposed to carbonyl and substrate stress, especially in conditions of hyperglycaemia, hyperlipidaemia and/or oxidative stress. Long lived proteins such as collagen are the main targets for advanced glycation endproducts formation. In particular, advanced glycation endproducts-mediated collagen overcrosslinking can cause loss of flexibility and elasticity and increased brittleness of tissues like bone (Ulrich and Cerami, 2001).

We have previously shown that soluble and matrix-associated advanced glycation endproducts can modulate osteoblastic growth and differentiation (McCarthy et al., 1997, 2001). In those experiments, we demonstrated that long-term exposure to advanced glycation endproducts-modified proteins significantly inhibited the proliferation, differentiation and mineralization of osteoblastic cultures. We also found that the advanced glycation endproducts-induced osteoblastic effects could be mediated by specific receptors such as receptor for advanced glycation endproducts-1 (McCarthy et al., 1999; Cortizo et al., 2003). Interestingly, other authors have recently reported that advanced glycation endproducts can stimulate osteoblast apoptosis through their interaction with receptor for advanced glycation endproducts- 1 , via the MAP kinase signaling pathway and caspase- 8 activation of caspase-3 (Alikhani et al., 2007).

In the present study we have evaluated whether $\mathrm{N}$-containing bisphosphonates are able to revert the deleterious effects of advanced glycation endproducts on osteoblasts in culture. To address this issue we have investigated the effects of advanced glycation endproducts with or without different bisphosphonates, on osteoblastic proliferation, differentiation, apoptosis, intracellular oxidative stress and neutral phosphatase activity in two osteoblastic cell lines in culture.

\section{Materials and methods}

\subsection{Materials}

Alendronate [1-hydroxy-3-aminobutylidene-1,1-bisphosphonic acid] was provided by Elea Laboratories (Argentina); Pamidronate [1-hydroxy-3-aminopropylidene-1,1-bisphosphonic acid, disodium salt] and Zoledronate [2-(imidazol-1-yl)-hydroxyethylidene-1,1bisphosphonic acid, disodium salt] were provided by Novartis (Basel, Switzerland). Dulbecco's modified Eagle's medium (DMEM), trypsinEDTA and foetal bovine serum were obtained from Gibco (Invitrogen, Buenos Aires, Argentina). Tissue culture disposable material was from Nunc (Tecnolab, Buenos Aires, Argentina). Centricon $10 \mathrm{kDa}$ cutoff filter cartridges were purchased from Amicon Inc. (Beverly, Mass., USA). Bovine serum albumin, D-glycolaldehyde, Triton X-100 and Sirius Red dye were obtained from Sigma-Aldrich (Buenos Aires, Argentina). Di-hydro-rhodamine 123 (DHR), annexin V-FITC, propidium iodide (PI) and fluorogenic small substrate 6,8-difluoro-4methylumbelliferyl 86 phosphate (DiFMUP) were from Molecular Probes (Buenos Aires, Argentina). All other chemicals and reagents were purchased from commercial sources and were of analytical grade.

\subsection{Preparation of advanced glycation endproducts}

Advanced glycation endproducts-modified bovine serum albumin was prepared by incubation of $10 \mathrm{mg} / \mathrm{ml}$ bovine serum albumin with $33 \mathrm{mM}$ D-glycolaldehyde in $150 \mathrm{mM}$ phosphate-buffered saline pH 7.4 at $37{ }^{\circ} \mathrm{C}$ for 3 days under sterile conditions (Unno et al., 2004). D-glycolaldehyde was used as the glycating sugar instead of glucose to speed up non-enzymatic glycosylation. Control bovine serum albumin was incubated in the same conditions without sugar. The unincorporated sugar was removed by centrifugation/filtration with Centricon filter cartridges. The formation of advanced glycation endproducts was assessed with an Aminco-Bowman SPF100 spectrofluorometer by their characteristic fluorescence-emission maximum at $420 \mathrm{~nm}$ upon excitation at $340 \mathrm{~nm}$. The estimated levels of advanced glycation endproducts-modified bovine serum albumin obtained in this in vitro incubation were $18.5 \%$ relative fluorescence intensity/mg protein, in contrast to $3.2 \%$ for control bovine serum albumin.

\subsection{Cell cultures and incubations}

UMR106 rat osteosarcoma cells and MC3T3E1 mouse calvariaderived cells were grown in DMEM containing 10\% foetal bovine serum, $100 \mathrm{U} / \mathrm{ml}$ penicillin and $100 \mu \mathrm{g} / \mathrm{ml}$ streptomycin at $37^{\circ} \mathrm{C}$ in a $5 \%$ $\mathrm{CO}_{2}$ atmosphere (McCarthy et al., 1997). Cells were seeded on $75 \mathrm{~cm}^{2}$ flasks, sub-cultured using trypsin-EDTA and replated on multi-well plates. The UMR106 rat osteosarcoma-derived cell line has been shown to conserve certain characteristics of differentiated osteoblastic phenotype (Partridge et al., 1983). In the case of non-transformed MC3T3E1 mouse calvaria-derived osteoblastic cells, previous studies have demonstrated that expression of osteoblastic markers begins after culturing the cells with medium supplemented by $5 \mathrm{mM} \beta-$ glycerol-phosphate and $25 \mu \mathrm{g} / \mathrm{ml}$ ascorbic acid (Quarles et al., 1992). Under these culture conditions, alkaline phosphatase activity begins to be expressed after 1 week, while mineralization is achieved after extending the culture to 3 weeks. However, the cells only undergo active replication during the first 5 days of incubation. For proliferation, apoptosis and reactive oxygen species formation experiments in both cell lines, and differentiation experiments with UMR106 osteoblasts, cells seeded on multi-well plates were incubated in DMEM medium with different doses of bovine serum albumin or advanced glycation endproducts-modified bovine serum albumin, with or without bisphosphonates, during the periods of time indicated in the legends of figures. For alkaline phosphatase expression experiments with MC3T3E1 osteoblasts, cells were cultured for 1 week in DMEM/Foetal bovine serum supplemented with $\beta$-glycerol-phosphate and ascorbic acid changing the medium every 2 days, after which they were serum-starved and incubated in DMEM with different doses of bovine serum albumin or advanced glycation endproducts-modified bovine serum albumin, with or without bisphosphonates, for an additional $72 \mathrm{~h}$.

\subsection{Assays for osteoblast proliferation}

Cell proliferation was determined using the crystal violet mitogenic bioassay as described previously (Okajima et al., 1992), with some modifications. Briefly, cells were grown in 48-well plates and submitted to different experimental conditions in serum-free DMEM, 
according to the figure legends. Then, the monolayers were washed with phosphate-buffered saline and fixed with $5 \%$ glutaraldehyde/ phosphate-buffered saline at room temperature for $10 \mathrm{~min}$. After that they were stained with $0.5 \%$ crystal violet $/ 25 \%$ methanol for $10 \mathrm{~min}$. The dye taken up by the cells was extracted using $0.5 \mathrm{ml} /$ well $0.1 \mathrm{M}$ glycine/ $\mathrm{HCl}$ buffer, $\mathrm{pH} 3.0 / 30 \%$ methanol and transferred to test tubes. Absorbance was read at $540 \mathrm{~nm}$ after a convenient sample dilution. We have previously shown that, under these conditions, this colorimetric bioassay strongly correlates with cell proliferation measured by cell counting in Neubauer chambers (Cortizo and Etcheverry, 1995). In order to evaluate the possible role of calcium in the modulation of osteoblastic proliferation by advanced glycation endproducts and/or bisphosphonates, in certain experiments we also included $10 \mu \mathrm{M}$ Nifedipine in the incubation media.

\subsection{Assays for osteoblast differentiation}

Osteoblastic differentiation was evaluated by measuring alkaline phosphatase activity and type I collagen production. Alkaline phosphatase activity was assayed as we have previously described (Cortizo and Etcheverry, 1995). Briefly, the cell layer was washed with phosphate-buffered saline and solubilized in $0.5 \mathrm{ml} 0.1 \%$ Triton X-100. Aliquots of the total cell extract were used for protein determination by the Bradford technique (Bradford, 1976). Measurement of alkaline phosphatase was carried out by spectrophotometric determination of initial rates of hydrolysis of para-nitrophenyl-phosphate (p-NPP) to para-nitrophenol (p-NP) at $37{ }^{\circ} \mathrm{C}$ for $10 \mathrm{~min}$. The production of p-NP was determined by absorbance at $405 \mathrm{~nm}$. Under our experimental conditions p-NP formation was linear for $15 \mathrm{~min}$. Collagen production was evaluated with a Sirius red-based colorimetric microassay (Tullberg-Reinert and Jundt, 1999): cells were fixed in Bouin's fluid for $1 \mathrm{~h}$, washed with water and stained with Sirius red dye for $1 \mathrm{~h}$. The stained material was dissolved in $0.1 \mathrm{~N}$ sodium hydroxide and absorbance read at $550 \mathrm{~nm}$.

\subsection{Evaluation of cell death}

Apoptosis was evaluated using an annexin V-FITC/propidium iodide (PI) assay as we have previously described (Molinuevo et al., 2004). Early apoptotic stages were characterized by annexin V-FITCpositive/PI-negative $\left(\mathrm{V}^{+} / \mathrm{PI}^{-}\right)$staining, while apoptotic/necrotic stages were $\mathrm{V}^{+} / \mathrm{PI}^{+}$. The percentage of apoptotic and necrotic osteoblasts was determined by counting the cells per field in 20 fields per coverslip.

\subsection{Determination of intracellular reactive oxygen species formation}

Intracellular reactive oxygen species generation in osteoblastic cells was measured by oxidation of dihydro-rhodamine123(DHR) to rhodamine as we have previously described (McCarthy et al., 2001). Osteoblastic cell monolayers growing in 24-well plates were submitted to the culture conditions indicated in figure legends. Medium was replaced by phenol red-free DMEM with $10 \mu \mathrm{M}$ DHR and the cells were further incubated for $4 \mathrm{~h}$. After washing with phosphatebuffered saline, the monolayer was lysated in $0.1 \%$ Triton X-100.
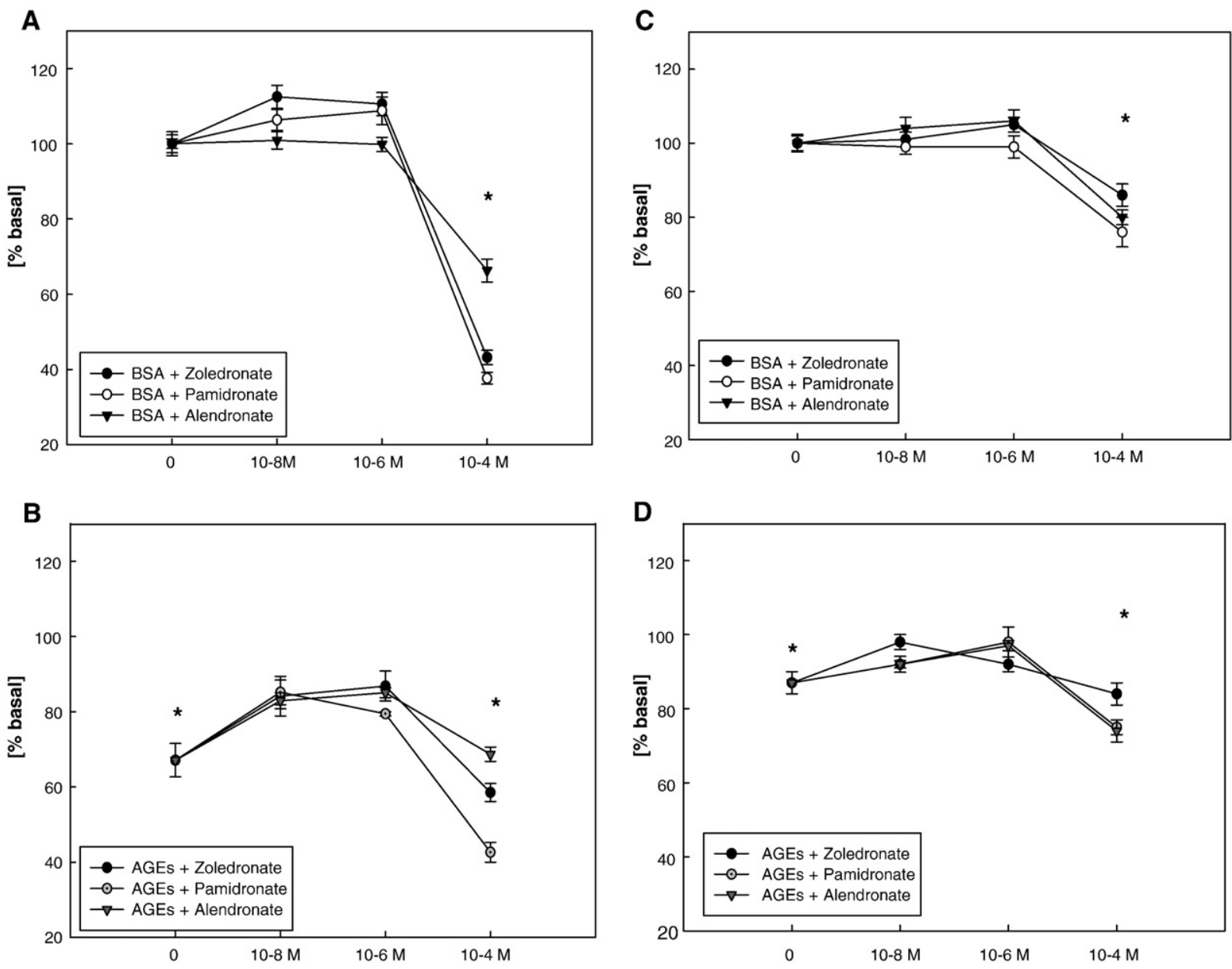

Fig. 1. Effect of advanced glycation endproducts (AGEs) and bisphosphonates on osteoblast proliferation. MC3T3E1 (A and B) or UMR106 (C and D) osteoblastic cells were incubated for $24 \mathrm{~h}$ with $100 \mu \mathrm{g} / \mathrm{ml}$ of either bovine serum albumin (BSA) (A and C) or AGEs-BSA (B and D), with or without different concentrations ( $10^{-4}, 10^{-6}$ or $10^{-8} \mathrm{M}$ ) of Alendronate, Pamidronate or Zoledronate. Cell proliferation was determined by the Crystal Violet method. Results have been referred to basal conditions (BSA alone), and are shown as the mean \pm S.E.M. $* P<0.01$. 


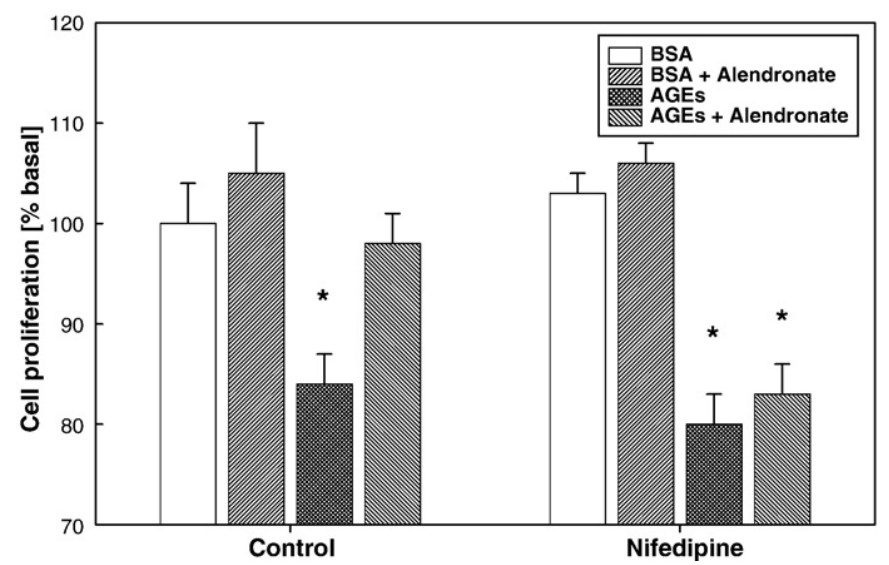

Fig. 2. Role of calcium in the modulation of osteoblastic proliferation by advanced glycation endproducts (AGEs) and bisphosphonates. MC3T3E1 osteoblasts were preincubated for $10 \mathrm{~h}$ in the presence or absence of $10 \mu \mathrm{M}$ of the calcium channel inhibitor Nifedipine (with or without $10^{-8} \mathrm{M}$ Alendronate), after which $100 \mu \mathrm{g} / \mathrm{ml}$ of either bovine serum albumin (BSA) or AGEs-BSA were added to the culture medium for an additional $14 \mathrm{~h}$. Cell proliferation was determined by the Crystal Violet method. Results have been referred to basal conditions (BSA alone), and are shown as the mean \pm S.E.M. $* P<0.01$.

The concentration of oxidized product present in the cell extract (rhodamine), was determined with a spectrofluorometer (excitation wavelength $495 \mathrm{~nm}$, emission wavelength $532 \mathrm{~nm}$ ).

\subsection{Fluorogenic phosphatase assay}

In order to evaluate the effect of advanced glycation endproducts and bisphosphonates on the activity of osteoblastic neutral phosphatases, we carried out a fluorogenic assay. This assay was performed by incubating confluent UMR106 monolayers with $200 \mu \mathrm{g} / \mathrm{ml}$ of either bovine serum albumin or advanced glycation endproducts-modified bovine serum albumin plus different concentrations $\left(10^{-4}, 10^{-5}\right.$ or $\left.10^{-6} \mathrm{M}\right)$ of Alendronate for $24 \mathrm{~h}$. After that, an aliquot of cell lysates (50 $\mu \mathrm{g}$ of protein)

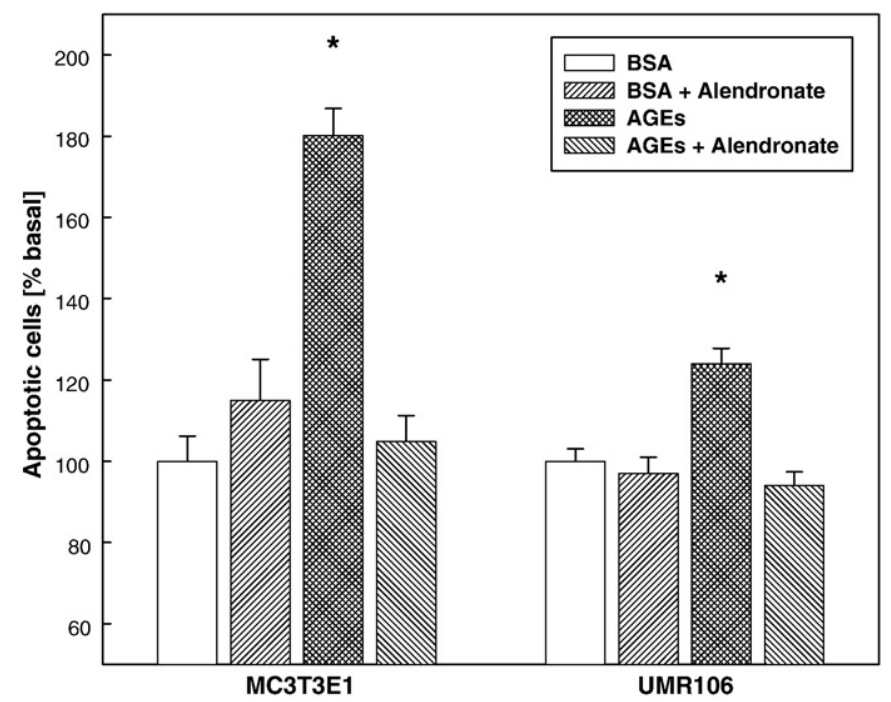

Fig. 3. Effect of advanced glycation endproducts (AGEs) and bisphosphonates on the induction of apoptosis in osteoblastic cells. UMR106 or MC3T3E1 osteoblastic cells were incubated for $24 \mathrm{~h}$ with $100 \mu \mathrm{g} / \mathrm{ml}$ of either bovine serum albumin (BSA) or AGEs-BSA, with or without $10^{-8} \mathrm{M}$ of Alendronate. Apoptosis was evaluated by Annexin V/Propidium Iodide staining, as described in Materials and methods. The percentage of apoptotic and necrotic osteoblasts was determined by counting the number of cells per field in 20 fields per coverslip. Results have been referred to basal conditions (BSA alone), and are shown as the mean \pm S.E.M. $* P<0.01$ were incubated with the fluorogenic substrate DiFMUP for $10 \mathrm{~min}$ as previously described (Molinuevo et al., 2007). The resulting fluorescent product was measured every minute at 360/450 nm (excitation/emission wavelengths) using an Aminco-Bowman SPF100 spectrofluorometer.

\subsection{Statistical analysis}

The results are expressed as the mean \pm S.E.M. and were obtained from three separate experiments performed in triplicate. Differences between the groups were assessed by Oneway ANOVA with Tukey post-hoc test. For non-normally distributed data, non-parametrical Kruskal Wallis with Dunn post-hoc test was performed using GraphPad In Stat version 3.00 (Graph Pad Software, San Diego, California, USA). A $P$ value $<0.05$ was considered significant for all statistical analyses.

\section{Results}

\subsection{Modulation of osteoblast proliferation. Role of intracellular calcium}

MC3T3E1 and UMR106 osteoblastic cells were incubated for $24 \mathrm{~h}$ with $100 \mu \mathrm{g} / \mathrm{ml}$ of either bovine serum albumin or advanced glycation
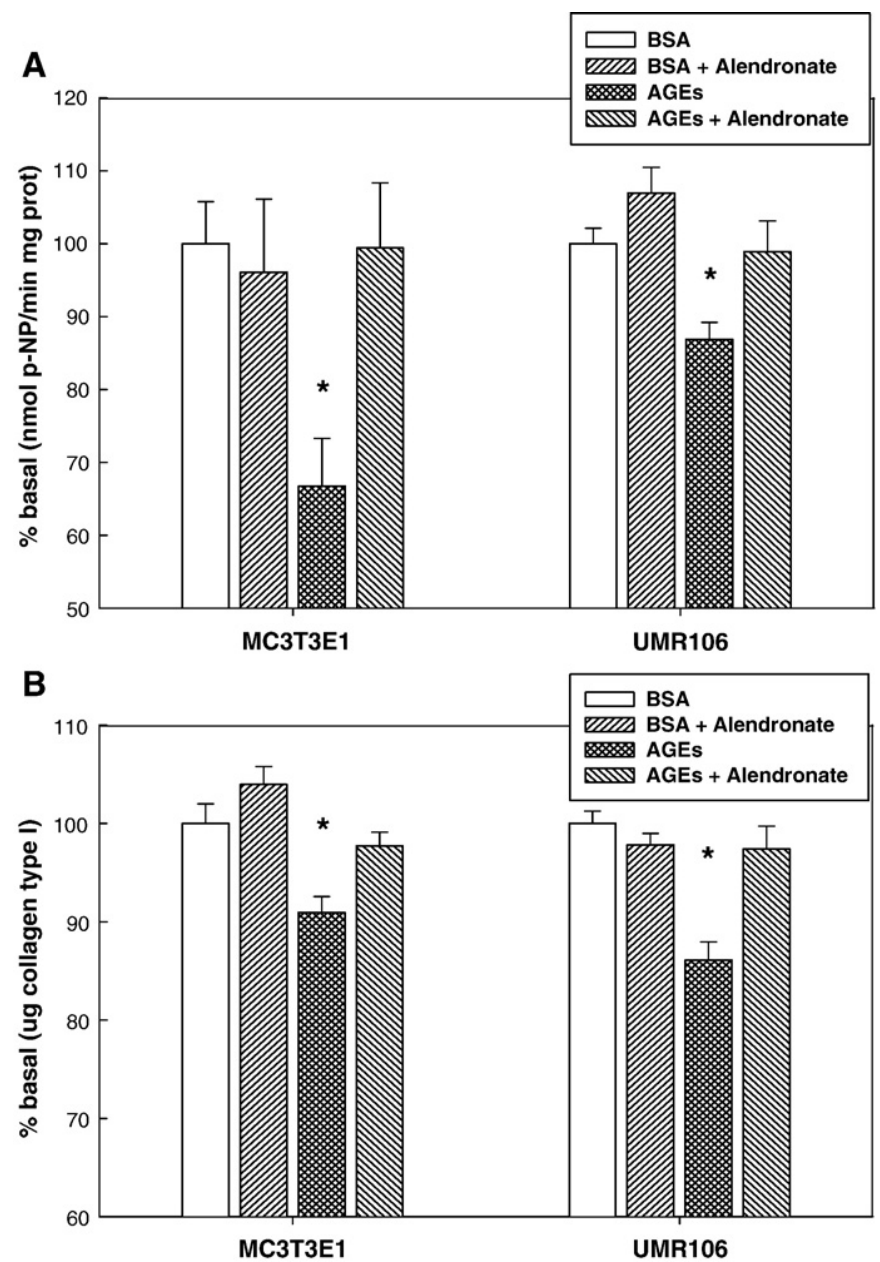

Fig. 4. Effect of advanced glycation endproducts (AGEs) and bisphosphonates on the differentiation of osteoblastic cells. MC3T3E1 osteoblasts (pre-treated with $\beta$-glycerolphosphate and ascorbic acid for a week) or $48 \mathrm{~h}$ cultures of UMR106 cells were further incubated for $72 \mathrm{~h}$ with $100 \mu \mathrm{g} / \mathrm{ml}$ of either bovine serum albumin (BSA) or AGEs-BSA, with or without $10^{-8} \mathrm{M}$ Alendronate. As described in Materials and methods, both cell lines were then evaluated for alkaline phosphatase expression (A), and for type 1 collagen production (B). Results have been referred to basal conditions (BSA alone), and are shown as the mean \pm S.E.M. $* P<0.01$. 


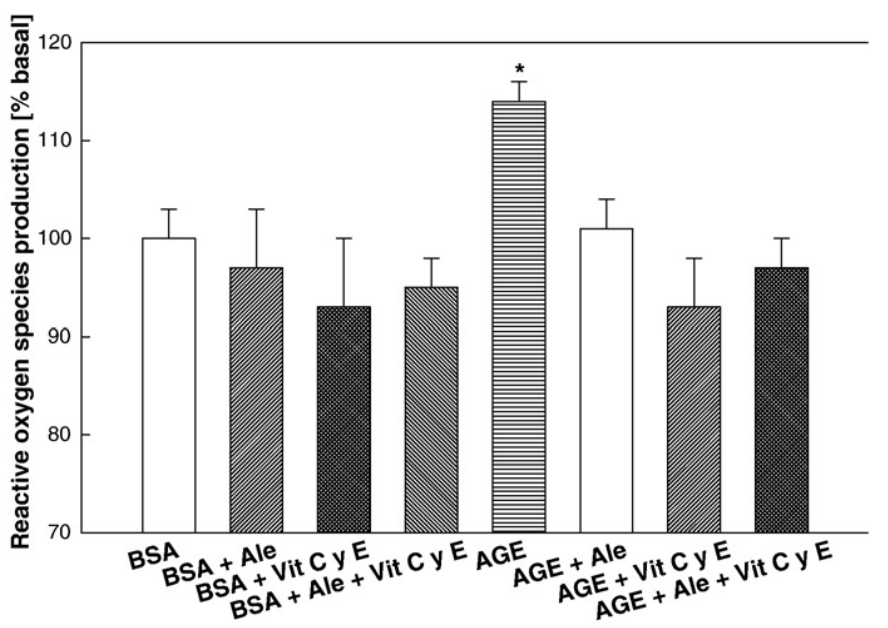

Fig. 5. Effect of advanced glycation endproducts (AGEs) and bisphosphonates on intracellular reactive oxygen species production. MC3T3E1 osteoblasts were incubated $24 \mathrm{~h}$ with $100 \mu \mathrm{g} / \mathrm{ml}$ of either bovine serum albumin (BSA) or AGEs-BSA, with or without $10^{-8} \mathrm{M}$ Alendronate (Ale) and in the presence or absence of $50 \mu \mathrm{M}$ of vitamins $\mathrm{C}$ and $\mathrm{E}$ (as anti-oxidants). Osteoblasts were then evaluated for intracellular reactive oxygen species production by the DHR method, as described in Materials and methods. Results have been referred to basal conditions (BSA alone), and are shown as the mean \pm S.E.M. $* P<0.01$.

endproducts-modified bovine serum albumin, with or without different concentrations $\left(10^{-8}, 10^{-6}\right.$ or $\left.10^{-4} \mathrm{M}\right)$ of Alendronate, Pamidronate or Zoledronate. These concentrations were chosen because in patients under treatment for osteoporosis with bisphosphonates, osteoblasts are believed to be exposed to levels equal or lower than $10^{-5} \mathrm{M}$ (Spreafico et al., 2006). After this incubation period, cell proliferation was evaluated by the Crystal Violet method. As can be seen in Fig. 1, advanced glycation endproducts-modified bovine serum albumin significantly diminished osteoblast proliferation, and this decrease was reverted by co-incubation with $10^{-8}$ or $10^{-6} \mathrm{M}$ Alendronate, Pamidronate or Zoledronate. However, co-incubation with higher concentrations $\left(10^{-4} \mathrm{M}\right)$ of all three bisphosphonates was toxic for osteoblasts, and this effect was independent of the presence of bovine serum albumin or advanced glycation endproductsmodified bovine serum albumin (Fig. 1). To evaluate the participation of intracellular calcium in this phenomenon, in some experiments we pre-incubated cells for $10 \mathrm{~h}$ with $10 \mu \mathrm{M}$ of the L-type voltage-sensitive calcium channel inhibitor Nifedipine (with or without $10^{-8} \mathrm{M}$ Alendronate), after which we added $100 \mu \mathrm{g} / \mathrm{ml}$ of either bovine serum albumin or advanced glycation endproducts-modified bovine serum albumin to the culture medium for an additional $14 \mathrm{~h}$. We found that although Nifedipine did not alter the advanced glycation endproducts-induced decrease in osteoblastic proliferation, it completely abrogated the Alendronate-dependent reversion of advanced glycation endproducts effects on osteoblastic growth (Fig. 2).

\subsection{Effect of advanced glycation endproducts and bisphosphonates on osteoblast apoptosis}

We postulated that the modulation of osteoblastic proliferation by advanced glycation endproducts and bisphosphonates could be at least partly due to opposing effects on the induction of cell apoptosis. Thus, MC3T3E1 and UMR106 osteoblastic cells were incubated for $24 \mathrm{~h}$ with $100 \mu \mathrm{g} / \mathrm{ml}$ of either control or advanced glycation endproducts-modified bovine serum albumin, with or without $10^{-8} \mathrm{M}$ Alendronate, after which they were evaluated for induction of apoptosis by the Annexin V/PI method as described in Materials and methods. Fig. 3 shows that in both osteoblastic cell lines advanced glycation endproducts induced a significant increase in apoptosis, which was however completely reverted by Alendronate.
3.3. Effects of advanced glycation endproducts and bisphosphonates on osteoblast differentiation

We next evaluated the effect of advanced glycation endproducts and bisphosphonates on the differentiation of osteoblastic cells. For this, MC3T3E1 osteoblasts (pre-treated with $\beta$-glycerol-phosphate and ascorbic acid for a week) or $48 \mathrm{~h}$ cultures of UMR106 osteosarcomaderived cells were further incubated for $72 \mathrm{~h}$ with $100 \mu \mathrm{g} / \mathrm{ml}$ of either control or advanced glycation endproducts-modified bovine serum albumin, with or without $10^{-8} \mathrm{M}$ Alendronate. After this incubation, both cell lines were evaluated for alkaline phosphatase expression and for type 1 collagen production, as described in Materials and methods. As can be seen in Fig. 4, in both cell lines advanced glycation endproducts significantly decreased alkaline phosphatase expression and type 1 collagen production. However, both deleterious effects were completely abrogated by co-incubation with Alendronate.

3.4. Effect of advanced glycation endproducts and bisphosphonates on intracellular reactive oxygen species production

Intracellular reactive oxygen species production is known to mediate certain effects of advanced glycation endproducts, particularly those

A

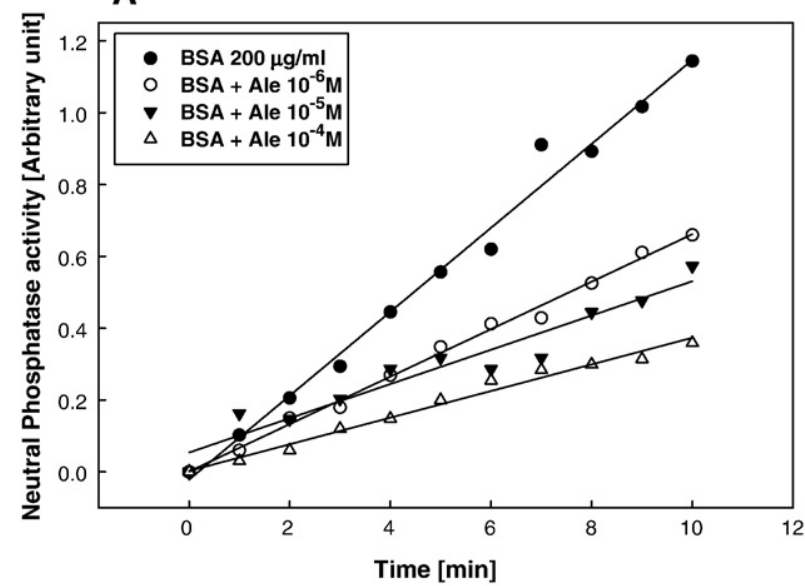

B

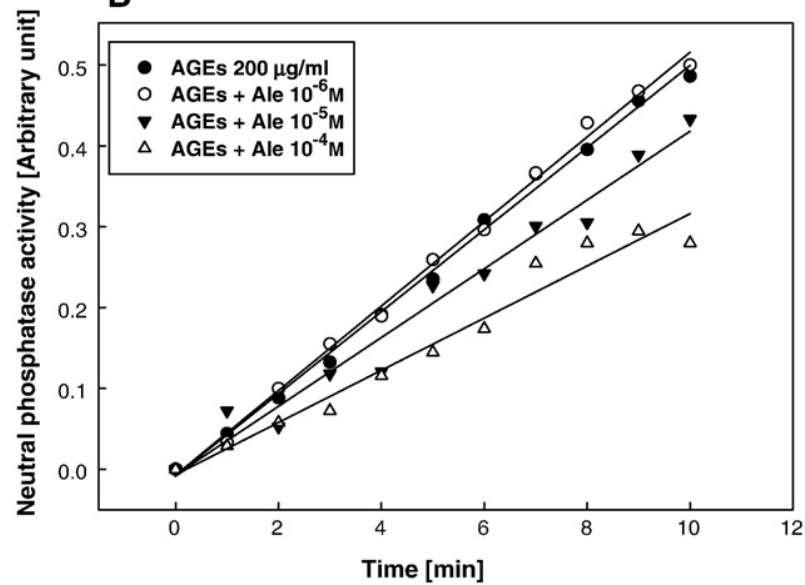

Fig. 6. Effect of advanced glycation endproducts (AGEs) and bisphosphonates on the activity of osteoblastic neutral phosphatases. Confluent monolayers of UMR106 osteoblastic cells were incubated for $24 \mathrm{~h}$ with $200 \mu \mathrm{g} / \mathrm{ml}$ of bovine serum albumin (BSA) or AGEs-BSA, plus different concentrations $\left(10^{-4}, 10^{-5}\right.$ or $\left.10^{-6} \mathrm{M}\right)$ of Alendronate (Ale). Aliquots of cell lysates ( $50 \mu \mathrm{g}$ of protein) were then incubated for $10 \mathrm{~min}$ with the fluorogenic substrate DiFMUP, and the resulting fluorescent product was measured every minute as described in Materials and methods. For each experimental condition, slopes were calculated by regression analysis in order to determine the activity of total neutral phosphatases, and these are shown in Table 1. 
Table 1

Effect of bovine serum albumin (BSA), advanced glycation endproducts (AGEs) and different doses of Alendronate on the activity rate of total neutral phosphatases in UMR106 osteoblastic cells

\begin{tabular}{|c|c|c|}
\hline \multirow[t]{2}{*}{ Condition } & \multirow{2}{*}{$\frac{\text { Activity rate }}{\text { [as \% of BSA 200] }}$} & \multirow{2}{*}{$\frac{\text { Activity rate }}{\text { [as \% of AGEs 200] }}$} \\
\hline & & \\
\hline BSA $200 \mu \mathrm{g} / \mathrm{ml}$ & 100 & - \\
\hline BSA $200+10^{-6}$ M Alendronate & 57 & - \\
\hline BSA $200+10^{-5} \mathrm{M}$ Alendronate & 41 & - \\
\hline BSA $200+10^{-4}$ M Alendronate & 32 & - \\
\hline AGEs $200 \mu \mathrm{g} / \mathrm{ml}$ & 43 & 100 \\
\hline AGEs $200+10^{-6}$ M Alendronate & 45 & 103 \\
\hline AGEs $200+10^{-5} \mathrm{M}$ Alendronate & 36 & 83 \\
\hline AGEs $200+10^{-4} \mathrm{M}$ Alendronate & 27 & 63 \\
\hline
\end{tabular}

which depend on recognition of advanced glycation endproducts by the receptor of advanced glycation endproducts. Thus, we set out to evaluate whether this signal transduction pathway is involved in the modulation of osteoblasts by advanced glycation endproducts and bisphosphonates. For this, we incubated osteoblastic cells with $100 \mu \mathrm{g} / \mathrm{ml}$ of either bovine serum albumin or advanced glycation endproducts-modified bovine serum albumin, with or without $10^{-8} \mathrm{M}$ Alendronate and in the presence or absence of $50 \mu \mathrm{M}$ of vitamins $\mathrm{C}$ and $\mathrm{E}$ (as anti-oxidants), after which the osteoblasts were evaluated for intracellular reactive oxygen species production by the DHR method. Fig. 5 shows that osteoblastic cells exposed to advanced glycation endproducts significantly increased their intracellular production of reactive oxygen species. However, this increase was completely curbed in the presence of Alendronate and/or anti-oxidants.

\subsection{Effect of advanced glycation endproducts and bisphosphonates on the activity of neutral phosphatases}

In this study we also evaluated the modulation of intracellular neutral phosphatases by bisphosphonates, as another possible mechanism for the regulation of osteoblastic development. For this, confluent monolayers of osteoblastic cells were incubated for $24 \mathrm{~h}$ with control or advanced glycation endproducts-modified bovine serum albumin, plus different concentrations of Alendronate. Cell lysates were then obtained and aliquots were incubated for $10 \mathrm{~min}$ with the fluorogenic substrate DiFMUP: the activity of total neutral phosphatases was determined by the rate of appearance of the fluorescent product. As can be seen in Fig. 6 and Table 1, we found that advanced glycation endproducts alone (Fig. 6B) inhibited neutral phosphatases activity by half (versus bovine serum albumin alone, Fig. $6 \mathrm{~A}$ ) and that this inhibition was similar to that observed for bovine serum albumin plus $10^{-6} \mathrm{M}$ Alendronate. However, there was no difference in neutral phosphatases activity between advanced glycation endproducts alone and advanced glycation endproducts plus $10^{-6} \mathrm{M}$ Alendronate (Fig. 6B). In the case of higher doses of Alendronate $\left(10^{-5}\right.$ and $\left.10^{-4} \mathrm{M}\right)$, which are compatible with a significant chelation of divalent cations, a dosedependent inhibition of neutral phosphatases activity was observed with both bovine serum albumin and advanced glycation endproductsmodified bovine serum albumin.

\section{Discussion}

Advanced glycation endproducts accumulate in various tissues in patients with Diabetes mellitus, and have been implicated in the development and progression of diabetic chronic complications (Ulrich and Cerami, 2001; Brownlee, 2005). These complications include a decrease in bone formation and turnover, which has been studied by various authors (Bouillon, 1991; Krakauer et al., 1995; Schwartz, 2003). In particular, Krakauer et al. (1995) in a 12-year follow-up clinical study, showed that osteoblastic extracellular matrix production and mineralization was significantly impaired in patients with type 1 and type 2 Diabetes mellitus. Although the precise mechanisms by which long-standing Diabetes may affect bone are incompletely known, the accumulation of advanced glycation endproducts in bone tissue is believed to be one of the main culprits (Schwartz, 2003). We have previously shown that advanced glycation endproducts can directly affect the growth and differentiation of osteoblasts (McCarthy et al., 1997, 2001). These actions seem to be mediated through the activation of specific receptors for advanced glycation endproducts, which we have described in osteoblastic cells (McCarthy et al., 1999; Cortizo et al., 2003).

Bisphosphonates are probably the most widely used family of antiosteoporotic drugs, and although their primary actions target osteoclastic function and survival, they have also recently been shown to positively influence osteoblastic development and bone-forming potential (Tsuchimoto et al., 1994; Plotkin et al., 1999; Viereck et al., 2002). Bisphosphonates are utilized in patients with Diabetes mellitus and osteoporosis, although with conflicting results (Dagdelen et al., 2007; Yamauchi, 2007). Recently, an anti-advanced glycation endproducts effect of $\mathrm{N}$-containing bisphosphonates has been postulated (Yamagishi et al., 2006): in experiments with human umbilical vein endothelial cells (HUVECS), Yamagishi and co-workers have shown that Incadronate and Minodronate can revert deleterious effects of advanced glycation endproducts (Okamoto et al., 2002; Yamagishi et al., 2005). This beneficial action of these bisphosphonates was found to be due to a suppression of NADPH oxidase-derived intracellular reactive oxygen species generation, probably via inhibition of geranyl-geranylation of Rac: NADPH oxidase-derived reactive oxygen species generation is required for advanced glycation endproductsReceptor for advanced glycation endproducts signaling in vascular wall cells, and small $G$ protein Rac is a critical component of the NADPH oxidase complex.

Since orally absorbed bisphosphonates primarily localize to sites of actively remodeling bone tissue, in this work we set out to investigate whether $\mathrm{N}$-containing bisphosphonates could revert the deleterious effects of advanced glycation endproducts on osteoblasts, which we have described previously (McCarthy et al., 1997, 2001). Our present results support this hypothesis, and evidence for this notion is based on the following observations: (a) advanced glycation endproducts induce in osteoblasts both an increase in apoptosis and a decrease in cell proliferation, and both effects are reverted by low doses of bisphosphonates. (b) advanced glycation endproducts impair osteoblastic bone-forming potential since they diminish both alkaline phosphatase specific activity and type 1 collagen production; however, these deleterious actions of advanced glycation endproducts are completely abrogated by low concentrations of bisphosphonates.

This reversion by bisphosphonates of the anti-proliferative effect of advanced glycation endproducts, can be at least partly accounted for by the anti-apoptotic action of bisphosphonates which we show in the present work, and which has also been reported by other authors (Plotkin et al., 1999, 2006). However, it could also be due to apoptosisindependent mechanisms. Mathov et al. (2001) have demonstrated that bisphosphonates can directly increase the proliferation of osteoblasts via activation of extracellular signal-regulated kinases and calcium influx. This led us to investigate whether in our culture conditions the effects of bisphosphonates on osteoblast proliferation were calcium-dependent: using Nifedipine we have shown that although the anti-proliferative effects of advanced glycation endproducts are calcium-independent, the reversion of such effects by bisphosphonates requires influx of $\mathrm{Ca}^{2+}$ through L-type voltage-sensitive calcium channels.

Different authors have investigated the direct modulation by $\mathrm{N}$-containing bisphosphonates of osteoblastic alkaline phosphatase activity and type 1 collagen expression. Overall, they have found that bisphosphonates induce a significant increase in both parameters of osteoblast differentiation (Fromigué and Body, 2002; Spreafico et al., 2006; Boanini et al., 2008). These observations are in agreement with 
our present results, in which we have found a complete reversal by Alendronate of the inhibition by advanced glycation endproducts of osteoblastic alkaline phosphatase specific activity and type 1 collagen production.

All in all, if our present results could be extrapolated to a clinical setting, they would signify a return to normality both in the working time and in the maturation of osteoblasts exposed simultaneously to an advanced glycation endproducts-enriched bone extracellular matrix and to $\mathrm{N}$-containing bisphosphonates, possibly leading to an adequate osteoblastic bone-forming capacity.

In an attempt to define molecular mechanisms which could be operating for both advanced glycation endproducts and bisphosphonates in osteoblasts, we evaluated the intracellular production of reactive oxygen species and found that $10^{-8} \mathrm{M}$ Alendronate completely curbed the advanced glycation endproducts-induced increase in reactive oxygen species production. These results are in agreement with the reports of other authors, in which HUVECS were cultured with advanced glycation endproducts and bisphosphonates (Okamoto et al., 2002; Yamagishi et al., 2005): in their culture conditions, bisphosphonates were found to suppress the advanced glycation endproducts-induced NADPH oxidase-derived intracellular reactive oxygen species generation, via inhibition of geranyl-geranylation of Rac. Although we have not directly proven it, the same modulation of signal transduction mechanisms is probably operating under our experimental conditions.

We have previously shown that different doses of bisphosphonates can inhibit both neutral and alkaline osteoblastic phosphatases (Vaisman et al., 2005; Molinuevo et al., 2007). In addition, other investigators have demonstrated that intracellular protein phosphorylation is essential for the process of osteoblastic differentiation (Xiao et al., 2002). Thus, in the present work we evaluated the possible modulation of total osteoblastic neutral phosphatase activity by advanced glycation endproducts and bisphosphonates. Our present results are compatible with the following interpretation: high doses of Alendronate $\left(10^{-5}-10^{-4} \mathrm{M}\right)$ could be inhibiting neutral phosphatases which are dependent on divalent cations for their function. On the other hand, both advanced glycation endproducts and lower doses of Alendronate $\left(10^{-6} \mathrm{M}\right)$ could be inhibiting mainly divalent cation-independent neutral phosphatases (such as tyrosine phosphatases). Interestingly, we have previously shown that osteoblastic neutral phosphatase activity decreases by $45 \%$ in the presence of Vanadate (an inhibitor of tyrosine phosphatases) (Molinuevo et al., 2007), which is a degree of inhibition similar to that which we have found for advanced glycation endproducts and for $10^{-6} \mathrm{M}$ Alendronate in the present study.

In conclusion, in the present study we have shown that $\mathrm{N}$-containing bisphosphonates are effective in reverting the deleterious actions of advanced glycation endproducts on osteoblasts in culture, and that these effects of bisphosphonates depend on: (a) influx of $\mathrm{Ca}^{2+}$ through L-type voltage-sensitive calcium channels, and (b) blockage of intracellular reactive oxygen species generation. In addition, we have found that both advanced glycation endproducts and bisphosphonates can inhibit the activity of intracellular neutral phosphatases. Although further studies are required to evaluate whether these effects of bisphosphonates are operative in vivo and in a clinical setting, our findings support the results of reports which show a beneficial action of $\mathrm{N}$-containing bisphosphonates in patients with Diabetes mellitus and osteoporosis (Yamauchi, 2007).

\section{Acknowledgments}

We wish to thank Dr. J. Green - Novartis for the provision of Zoledronate and Pamidronate, and Dr. Ostrowsky - Laboratorios Elea Argentina for the donation of Alendronate. This study was partially supported by grants from Universidad Nacional de La Plata, Agencia Nacional de Promoción Científica y Tecnológica (A.N.P.C.y T.) (B.I.D.-1728/ O.C.-A.R., P.A.E. No 22398) and Comisión de Investigaciones Científicas de la provincia de Buenos Aires (C.I.C.P.B.A.). M.V.G. is a fellow of C.I.C.P.B.A., V.A. is a fellow of C.O.N.I.C.E.T. and A.M.C. is a member of the Carrera del Investigador, C.I.C.P.B.A.

\section{References}

Alikhani, M., Alikhani, Z., Boyd, C., MacLellan, C.M., Raptis, M., Liu, R., 2007. Advanced glycation end products stimulate osteoblast apoptosis via MAP kinase and cytosolic apoptotic pathways. Bone 40, 345-353.

Al-Mashat, H.A., Kandru, S., Liu, R., Behl, Y., Desta, T., Graves, D.T., 2006. Diabetes enhances mRNA levels of proapoptotic genes and caspase activity which contribute to impaired healing. Diabetes 55, 487-495.

Boanini, E., Torricelli, P., Gazzano, M., Giardino, R., Bigi, A., 2008. Alendronate-hydroxyapatite nanocomposites and their interaction with osteoclasts and osteoblast-like cells. Biomaterials 29, 790-796.

Bouillon, R., 1991. Diabetic bone disease. Calcif. Tissue Int. 49, 155-160.

Bradford, M.M., 1976. A rapid and sensitive method for the quantitation of microgram quantities of protein utilizing the principle of protein-dye binding. Anal. Biochem. 72, 248-254.

Brownlee, M., 2005. The pathobiology of diabetic complications: a unifying mechanism. Diabetes 54, 1615-1625.

Cortizo, A.M., Etcheverry, S.B., 1995. Vanadium derivatives act as growth factor-mimetic compounds upon differentiation and proliferation of osteoblast-like UMR106 cells. Mol. Cell Biochem. 145, 97-102.

Cortizo, A.M., Lettieri, M.G., Barrio, D.A., Mercer, N., Etcheverry, S.B., McCarthy, A.D., 2003. Advanced glycation endproducts (AGEs) induce concerted changes in the osteoblastic expression of their receptor RAGE and in the activation of extracellular signal-regulated kinases (ERK). Mol. Cell Biochem. 250, 1-10.

Dagdelen, S., Sener, D., Bayraktar, M., 2007. Influence of type 2 diabetes mellitus on bone mineral density response to bisphosphonates in late postmenopausal osteoporosis. Adv. Ther. 24, 1314-1320.

Fromigué, O., Body, J.J., 2002. Bisphosphonates influence the proliferation and the maturation of normal human osteoblasts. J. Endocrinol. Invest. 25, 539-546.

Green, J.R., 2005. Skeletal complications of prostate cancer: pathophysiology and therapeutic potential of bisphosphonates. Acta Oncol. 44, 282-292.

Krakauer, J.C., McKenna, M.J., Buderer, N.F., Rao, D.S., Whitehouse, F.W., Parfitt, A.M., 1995. Bone loss and bone turnover in diabetes. Diabetes 44, 775-782.

Mathov, I., Plotkin, L.I., Sgarlata, C.L., Leoni, J., Bellido, T., 2001. Extracellular signalregulated kinases and calcium channels are involved in the proliferative effect of bisphosphonates on osteoblastic cells in vitro. J. Bone Miner. Res. 16, 2050-2056.

McCarthy, A.D., Etcheverry, S.B., Bruzzone, L., Cortizo, A.M., 1997. Effects of advanced glycation end-products on the proliferation and differentiation of osteoblast-like cells. Mol. Cell Biochem. 170, 43-51.

McCarthy, A.D., Etcheverry, S.B., Cortizo, A.M., 1999. Advanced glycation endproductspecific receptors in rat and mouse osteoblast-like cells: regulation with stages of differentiation. Acta Diabetol. 36, 45-52.

McCarthy, A.D., Etcheverry, S.B., Bruzzone, L., Lettieri, G., Barrio, D.A., Cortizo, A.M. 2001 Non-enzymatic glycosylation of a type I collagen matrix: effects on osteoblastic development and oxidative stress. B.M.C. Cell Biol. 2, 16.

Molinuevo, M.S., Barrio, D.A., Cortizo, A.M., Etcheverry, S.B., 2004. Antitumoral properties of two new vanadyl(IV) complexes on osteoblasts in culture. Role of apoptosis and oxidative stress. Cancer Chemother. Pharmacol. 53, 163-172.

Molinuevo, M.S., Bruzzone, L., Cortizo, A.M., 2007. Alendronate induces anti-migratory effects and inhibition of neutral phosphatases in UMR106 osteosarcoma cells. Eur. J Pharmacol. 562, 28-33.

Okajima, T., Nakamura, K., Zhang, H., Ling, N., Tanabe, T., Yasuda, T., 1992. Sensitive colorimetric bioassays for insulin-like growth factor (IGF) stimulation of cell proliferation and glucose consumption: use in studies of IGF analogs. Endocrinology 130, 2201-2212.

Okamoto, T., Yamagishi, S., Inagaki, Y., Amano, S., Takeuchi, M., Kikuchi, S., 2002. Incadronate disodium inhibits advanced glycation end products-induced angiogenesis in vitro. Biochem. Biophys. Res. Commun. 297, 419-424.

Partridge, N.C., Alcorn, D., Michelangeli, V.P., Ryan, G., Martin, T.J., 1983. Morphologica and biochemical characterization of four clonal osteogenic sarcoma cell lines of rat origin. Cancer Res 43, 4308-4312.

Plotkin, L.I., Weinstein, R.S., Parfitt, A.M., Roberson, P.K., Manolagas, S.C., Bellido, T., 1999 Prevention of osteocyte and osteoblast apoptosis by bisphosphonates and calcitonin. J. Clin. Invest. 104, 1363-1374.

Plotkin, L.I., Manolagas, S.C., Bellido, T., 2006. Dissociation of the pro-apoptotic effects of bisphosphonates on osteoclasts from their anti-apoptotic effects on osteoblasts/ osteocytes with novel analogs. Bone 39, 443-452.

Quarles, L.D., Yahay, D.A., Lever, L.W., Caton, R., Wenstrup, R.J., 1992. Distinct proliferative and differentiated stages of murine MC3T3E1 cells in culture: an in vitro model of osteoblast development. J. Bone Miner. Res. 7, 683-692.

Rogers, M.J., 2003. New insights into the molecular mechanisms of action of bisphosphonates. Curr. Pharm. Des. 9, 2643-2658.

Rogers, M.J., Gordon, S., Benford, H.L., Coxon, F.P., Luckman, S.P., Monkkonen, J., 2000. Cellular and molecular mechanisms of action of bisphosphonates. Cancer 88 2961-2978.

Schwartz, A.V., 2003. Diabetes mellitus: does it affect bone? Calcif. Tissue Int. 73, $515-519$.

Schwartz, A.V., Sellmeyer, D.E., Ensrud, K.E., Cauley, J.A., Tabor, H.K., Schreiner, P.J., 2001 Older women with Diabetes have an increased risk of fracture: a prospective study. J. Clin. Endocrinol. Metab. 86, 32-38. 
Spreafico, A., Frediani, B., Capperucci, C., Gambera, D., Ferrata, P., Baldi, F., 2006. Anabolic effects and inhibition of interleukin 6 production induced by neridronate on human osteoblasts. Reumatismo 58, 288-300.

Strotmeyer, E.S., Cauley, J.A., Schwartz, A.V., Nevitt, M.C., Resnick, H.E., Bauer, D.C., 2005. Non traumatic fracture risk with diabetes mellitus and impaired fasting glucose in older white and black adults: the health, aging and body composition study. Ann. Intern. Med. 165, 1612-1617.

Tsuchimoto, M., Azuma, Y., Higuchi, O., Sugimoto, I., Hirata, N., Kiyoki, M., 1994. Alendronate modulates osteogenesis of human osteoblastic cells in vitro. Jpn. J. Pharmacol. 66, 25-33.

Tullberg-Reinert, H., Jundt, G., 1999. In situ measurement of collagen synthesis by human bone cells with a Sirius red-based colorimetric microassay: effects of transforming growth factor beta2 and ascorbic acid 2-phosphate. Histochem. Cell Biol. 112, 271-276.

Ulrich, P., Cerami, A., 2001. Protein glycation, diabetes, and aging. Recent. Prog. Horm. Res. 56, 1-21.

Unno, Y., Sakai, M., Sakamoto, Y., Kuniyasu, A., Nakayama, H., Nagai, R., 2004. Advanced glycation end products-modified proteins and oxidized LDL mediate down-regulation of leptin in mouse adipocytes via CD36. Biochem. Biophys. Res. Commun. 325, 151-156.

Vaisman, D.N., McCarthy, A.D., Cortizo, A.M., 2004. Bisphosphonates affect the growth, differentiation and cytoskeleton of UMR106 osteoblasts in culture. Osteoporos Int. 15 (Suppl.1), S133.
Vaisman, D.N., McCarthy, A.D., Cortizo, A.M., 2005. Bone-specific alkaline phosphatase activity is inhibited by bisphosphonates: role of divalent cations. Biol. Trace Elem. Res. 104, 131-140.

Viereck, V., Emons, G., Lauck, V., Frosch, K.H., Blaschke, S., Grundker, C., 2002. Bisphosphonates pamidronate and zoledronic acid stimulate osteoprotegerin production by primary human osteoblasts. Biochem. Biophys. Res. Commun. 291, 680-686.

Xiao, G., Gopalakrishnan, R., Jiang, D., Reith, E., Benson, M.D., Franceschi, R.T., 2002. Bone morphogenetic proteins, extracellular matrix, and mitogen-activated protein kinase signaling pathways are required for osteoblast-specific gene expression and differentiation in MC3T3-E1 cells. J. Bone Miner. Res. 17, 101-110.

Yamagishi, S., Matsui, T., Nakamura, K., Takeuchi, M., 2005. Minodronate, a nitrogencontaining bisphosphonate, inhibits advanced glycation end product-induced vascular cell adhesion molecule-1 expression in endothelial cells by suppressing reactive oxygen species generation. Int. J. Tissue React. 27, 189-195.

Yamagishi, S., Nakamura, K. Matsui, T. Takeuchi, M., 2006. Minodronate, a nitrogencontaining bisphosphonate, is a promising remedy for treating patients with diabetic retinopathy. Med. Hypothesis 66, 273-275.

Yamauchi, M., 2007. World Health Organization. Absolute risk for fracture and WHO guideline. Treatment of patients with secondary osteoporosis. Clin. Calcium 17, 1106-1113. 